\section{GES.04 - Estudo exploratório do cenário mundial de biossimilares e comparação entre agências regulatórias nos temas: intercambialidade, extrapolação de indicação e nomenclatura}

Hugo G. T. Defendi ${ }^{1 *}$; Monique C. de M. Stávale ${ }^{1}$; Sheila B. Matsuoka ${ }^{1}$.

1Fiocruz/Bio-Manguinhos.

\section{Introdução:}

Biossimilares, conceitualmente, possuem a mesma sequência de aminoácidos dos seus produtos biológicos de referência, porém considera-se que são produzidos a partir de diferentes clones, podendo ter processos de manufatura distintos. Estes são comercializados após a expiração das patentes dos medicamentos de referência. A somatropina foi o primeiro biossimilar a ser registrado no mundo (2006), abrindo precedente para muitos outros. Desde então, este mercado cresce virtuosamente, da mesma maneira que suscita questões importantes. A relevância dos biossimilares é indiscutível, pois promove maior acessibilidade aos produtos de base biotecnológica, que por terem processo de desenvolvimento complexo e serem geralmente de uso contínuo, tornam-se tratamentos de alto custo. Diante deste cenário dinâmico, que envolve a participação de vários atores, torna-se indispensável a discussão sobre o tema e ações que possibilitem maior entrada dos biossimilares no mercado.

\section{Objetivo:}

Realizar análise exploratória do cenário mundial de biossimilares e levantamento comparativo das posições das principais agências regulatórias acerca da intercambialidade, extrapolação de indicação e nomenclatura.

\section{Metodologia:}

Para análise exploratória do cenário mundial de biossimilares, utilizou-se a base de dados MedTrack, e consulta dos biossimilares aprovados nas páginas das agências regulatórias: ANVISA, FDA e EMA. A comparação das posições das agências sobre os temas propostos foi realizada através de busca em artigos, guias e documentos técnicos elaborados pelas próprias agências, consulta nos sítios eletrônicos e participação de debates técnicos sobre o assunto em fóruns variados.

\section{Resultado:}

Foram identificados 891 produtos classificados como biossimilares, mundialmente, sendo 353 aprovados. Destes, a classe terapêutica predominante é a oncológica, com 322 no total, dos quais 115 receberam aprovação. Os biossimilares aprovados pelas agências europeia (38) e americana (9) representam uma parcela pequena, porém considerada mais regulada. A ANVISA, seguindo bases similares aprovou 3 biossimilares. No que diz respeito à intercambialidade, a ANVISA entende que a política e diretrizes sobre este tema deverão ser definidas pelos médicos e MS. A posição do EMA é não regular a intercambialidade, deixando esta decisão para os países, enquanto que o FDA foi a única agência que publicou um guia, orientando as empresas em como alcançarem o status de intercambialidade. Em relação à nomenclatura, o FDA adotou nomenclatura diferente para os biossimilares, enquanto o EMA e ANVISA mantêm as nomenclaturas não proprietárias internacionais e nomes de marca como medida de rastreabilidade e farmacovigilância. A extrapolação de indicação terapêutica para biossimilares é possível nas três agências, com limitações de acordo com a população e PK/PD.

\section{Conclusão:}

A presente análise demonstra um grande esforço de empresas no desenvolvimento de biossimilares. Quanto aos aspectos abordados neste estudo, nota-se pouca normatização e harmonização entre as agências regulatórias, refletindo as diferentes opiniões dos vários atores envolvidos nestas discussões, o que torna a compreensão e estudo sobre o tema ainda mais relevantes.

Palavras-chave: biossimilar; intercambialidade; agências regulatórias 